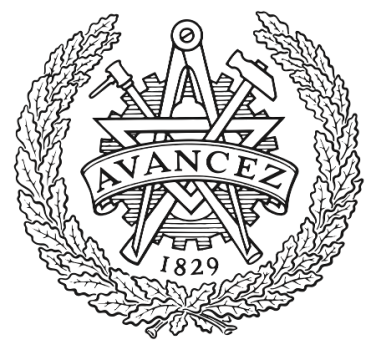

CHALMERS

UNIVERSITY OF TECHNOLOGY

\title{
Conceptualizing context in entrepreneurship education: a literature review
}

Downloaded from: https://research.chalmers.se, 2023-04-26 00:02 UTC

Citation for the original published paper (version of record):

Lindahl Thomassen, M., Williams Middleton, K., Breum Ramsgaard, M. et al (2020).

Conceptualizing context in entrepreneurship education: a literature review. International Journal of Entrepreneurial Behaviour and Research, 26(5): 863-886.

http://dx.doi.org/10.1108/IJEBR-04-2018-0258

N.B. When citing this work, cite the original published paper. 


\title{
Conceptualizing context in entrepreneurship education: a literature review
}

\author{
Mette Lindahl Thomassen \\ Department of Engineering, \\ VIA University College, Horsens, Denmark \\ Karen Williams Middleton \\ Department of Technology Management and Economics, \\ Chalmers University of Technology, Gothenburg, Sweden \\ Michael Breum Ramsgaard \\ Department of Health, VIA University College, Aarhus, Denmark \\ Helle Neergaard \\ Department of Management, Aarhus University, Aarhus, Denmark, and \\ Lorraine Warren \\ Massey University, Auckland, New Zealand
}

\begin{abstract}
Purpose - Context impacts the design and practice of entrepreneurship education, but there is limited focus on context in entrepreneurship education literature. The purpose of this paper is to review the entrepreneurship education literature to understand how context has been addressed, derives contextual elements from prioritized literature and explores how context can be adapted to and designed with in entrepreneurship education.

Design/methodology/approach - A systematic literature review is undertaken to explore context in entrepreneurship education literature. Context entrepreneurship education yielded 239 items. After refinement, 232 entrepreneurship education associated publications were reviewed by the team of authors. Using selection criteria, 26 prioritized publications were analyzed and categorized according to a theoretical framework.

Findings - Context has been addressed both conceptually and empirically, quantitatively and qualitatively, and can be categorized across three sociological phenomena levels - micro, meso and macro. Within these levels, more specific context elements emerge from the entrepreneurship education literature. The findings assert that while context is highly influential in relation to entrepreneurship education, it is arbitrarily described, and holds a variety of documented and diffuse elements. Educators have a limited span of control in relation to context elements, however, for the most parts elements can be adapted to or designed with. Finally, due to the influence of context it is difficult to identify a universal best practice of entrepreneurship education because there simply is no ceteris paribus.

Research limitations/implications - Contextual elements which emerged from the literature consider various subjects, spaces, structures and networks. Context is complex and has had limited treatment in entrepreneurship education literature, thus additional analysis and experimentation is necessary.

Practical implications - Context shapes understanding and influences learning. Addressing entrepreneurship education across three levels - micro, meso and macro - and through four framing questions - who, what, where and when - guides educators in how context influences and can be used when designing education.

Originality/value - The paper gives new insight into how context is addressed in entrepreneurship education literature, and how this can influence educational design.
\end{abstract}

Keywords Policy, Learning, Entrepreneurship education

Paper type Literature review

\section{Introduction}

Context is intuitively recognized and theoretical argued as important to entrepreneurship (Welter, 2011; Welter et al., 2016). However, there is less agreement on what constitutes context, as it can be conceptualized at several levels and through various elements (Zahra et al., 2014). Entrepreneurship research has argued for organization of context across five categories

Entrepreneurship education

Received 27 April 2018 Revised 26 August 2018 18 March 2019 19 June 2019 Accepted 30 June 2019 
(Goodman and Whetten, 1998; Welter, 2011) - historical, temporal, institutional, spatial and social. These categories are evident across the comprehensive spectrum of literature over the past 50 years, for example, illustrating links between national, regional and institutional culture and entrepreneurial potential (Autio et al., 2014; Mueller and Thomas, 2001; Shrivastava and Kennelly, 2013), entrepreneurial activity influenced by spatial conditions and local, social and economic milieu (Garofoli, 1994; Muñoz and Cohen, 2017), temporal interplay of context and action (Moroz and Hindle, 2011; Solymossy and Hisrich, 2000) or opportunity as conditioned by the entrepreneurs' interaction with their context (Gartner, 1985) and role in the social structure (Greenwood and Suddaby, 2006; Jack and Anderson, 2002).

Accepting that context matters to entrepreneurship because of interdependencies based upon interaction between the context and the entrepreneur (Welter et al., 2016), we need to better understand how context is dealt with when supporting entrepreneurial competence development. Thus, it seems odd that relatively little attention is given to context when designing entrepreneurial pedagogy and teaching entrepreneurship (Neergaard and Christensen, 2017). In this paper, we take a more stringent look at the literature to investigate how context has been addressed in entrepreneurship education, emphasizing work which positions context as a central focus rather than a peripheral contingency. We emphasize a pedagogical perspective in our analysis and conceptual implications.

One could argue that in algebra, for a given problem there is a right equation and there is a right answer, such that while what is learned is not dependent on where you are or who you are, but how it is learned is contextually dependent. Using theory of socially situated activity, Lave (2009) states that "decontextualized learning activity is a contradiction in terms" (p. 231). Lave argues for the relevance of context elements when designing and delivering education. In regard to entrepreneurship education, both what is learned and how it is learned is contextually dependent. There is no ceteris paribus (all other things being equal) in entrepreneurship education due to the complex multitude of variables that equate to a high degree of context dependency. Entrepreneurship education relies on experience and storytelling, rather than structured proofs, formulas or equations. For this reason, entrepreneurship education needs a contextualized perspective. As the tools of how to be or become entrepreneurial are not complete, entrepreneurship education needs context which is scaffolded (Neergaard and Christensen, 2017; Williams Middleton and Donnellon, 2014). Accordingly, we need to pay attention to context-specific aspects, when we design entrepreneurship education. It can be argued that not only context does matter (Barab and Plucker, 2002), but also it is foundational to any learning which is intended to be situated in practice, as it weaves together a multitude of factors influencing the learning processes that takes place (Cope, 2005).

This is particularly important as entrepreneurship education has seen a significant increase in the past decades (Kuratko, 2003; Nabi et al., 2017), with increasing attention on learning designed for gaining experience and preparing for practice (Lackéus et al., 2016; Robinson et al., 2016). Therefore, it would seem obvious that context constitutes a central theme for entrepreneurship education (and associated research). Yet, context as a variable has received scant specific attention in the entrepreneurship education literature, in comparison to the field in general (Welter, 2011; Welter et al., 2016), even though Walter and Dohse (2012) suggest that different results in relation to the impact of entrepreneurship education can be explained by differences in mode and setting of education. Blenker et al. (2014) underline the importance of being explicit about context in research within entrepreneurship education because it will enable comparison of studies, qualify the field and guide applicability. These arguments suggest that that the impact of context necessitates a pedagogic innovation. A better understanding of context in entrepreneurship education allows for a shift from addressing context solely as a setting we adhere to include context treated as a dynamic space that can be designed with. 
In this paper, we review the existing literature addressing context in entrepreneurship Entrepreneurship education in order develop a more clear and comprehensive understanding of context as an educational design parameter. Knowing what constitutes context will enable educators to education design with context, rather than in a context or devoid of context. We argue that it is important to be conscious of and attentive to context in entrepreneurship education, as context imprints preconceptions on the actors in the educational design - namely, the educators, students and practitioners - and also influences opportunities. In order to design with context, we therefore need to ask the following research questions:

$R Q 1$. What constitutes context in entrepreneurship education?

$R Q 2$. How can entrepreneurship education be developed with context as a design parameter?

The paper proceeds as follows. First, to premise the literature review, we provide an overview of how entrepreneurship and entrepreneurship education literature have been reviewed previously. We then present the methodological approach utilized to review literature for the purpose of this paper, addressing context and entrepreneurship education (through different keyword pairings). Insights from the review are then presented and discussed, culminating in suggestions for how these may inform entrepreneurship education design (and practice). Implications highlight the need for a conceptual framework which is aimed to raise awareness of context in entrepreneurship education, design and practice. The investigation points to areas for future theoretical development in entrepreneurship education research with regard to context, and practical implications suggest ways in which educators may make informed choices when designing with context in entrepreneurship education.

\section{Key issues from entrepreneurship education literature reviews}

Entrepreneurship education has been the subject of review studies for over two decades, with the journal Education and Training in particular providing a main forum (see e.g. Blenker et al., 2014; Henry and Lewis, 2018; Matlay, 2006; Matlay and Carey, 2007; Mwasalwiba, 2010). Context or contextualization has often been raised as an influential variable during these review studies. Context in these reviews have included both human and non-human actors (Latour, 2005) constituting the who, what, where and when of entrepreneurship educational context, henceforward described as context elements. The context elements addressed in the reviews can be divided across three sociological phenomena levels: the macro level, which are national context elements; the meso level that are regional and university specific context elements; and finally the micro level, which are the course specific elements. The earliest review (Gorman et al., 1997) capturing the ten previous years stresses the need for further studies on educational content and markets for education. In relation to context, these reviews draw attention to expanding multiplicity, both in terms of expansion across different university (ex. meso) and country (ex. macro) settings (Matlay, 2006), disciplines (ex. meso) and educational objectives, methods, content and assessment practice (ex. micro) (Mwasalwiba, 2010). Blenker et al. (2014) address methodology issues, seeking an integrative framework to try and improve how entrepreneurship is researched, aiming for better generalizability across contexts. Henry and Lewis (2018) provide a systematic review of previous entrepreneurship education reviews, noting once again that there is still a lack of generalizability in entrepreneurship education research not only because of limited conceptualisation and small samples, but also because of the range of different contexts: geographic institutional and programmes (again exemplifying macro, meso and micro levels). Naia et al. $(2014,2015)$ further found that best practices could be identified for a specific context, but there is no evidence that these practices could be extended to provide a universal approach. Similarly, theoretical grounding was contingent to the study context. 
Overall, the reviews emphasize key issues of concern in terms of weaknesses in methodology and theorization that undermines generalizability.

It is perhaps surprising that no review has positioned context as the main variable towards understanding entrepreneurship education, or recognized context as a design parameter, given the established connection between student intentionality, policy and context, for example, argued for by Pittaway and Cope (2007). Yet 10 years later, Longva and Foss (2018) still found that impact studies are marred by weakly understood linkages to context. Reviews of entrepreneurship education literature thus unveil two main concerns regarding context. One is the limitation and generalization in research due to contextual differences between studies. The other is the lack of progress in understanding context in relation to entrepreneurship education, both theoretically and in practice.

\section{Methodological approach}

To answer $R Q 1$ a systematic literature review collects all the different current perspectives on context, which inform the construction of a holistic understanding of context. A systematic literature review approach provides a stringent and prescribed methodology that allows researchers to make sense of large bodies of information (Petticrew and Roberts, 2006). This approach enables not only an overview of the literature but addresses what works and what does not. In this paper, the literature review is used to identify the partial and arbitrary descriptions of context in the current body of literature to inform an overarching understanding of the phenomena, putting together the pieces of the puzzle. In line with previous relevant systematic literature reviews (Henry and Lewis, 2018; Mwasalwiba, 2010; Tranfield et al., 2003), our design used a multiple keyword search to independently identify literature, followed by staged analysis to classify publications according to first general and then more specific criteria, while not excluding work based on methodological type.

A keyword search was conducted in the Scopus database in order to identify areas of overlap, as well as potential gaps in the literature, specifically peer-reviewed publications in books and journals. The keyword search utilized "Entrepreneurship Education" AND "Context", resulting in 239 articles, published between 1 January 1993 and 24 August 2017. The large majority (172 of 217) were published in 2010 or later. Seven publications from the initial search were excluded as they were not about higher education, published in a journal or book, or in English. This resulted in 232 remaining publications that were systematically reviewed by the authors of this paper. To capture initial key perspectives and current trends, a brief analysis of the 20 most cited publications as well as the 10 most recently published items was conducted (four articles published in 2017 and six articles published in 2016). This preliminary analysis informed the framework used for reviewing all the publications.

Two main filters were utilized to review the literature. First the literature was grouped into different classifications. Literature where context issues in entrepreneurship education were the central focus and relating to the aim of the piece were classified as "Main". Literature which has sections focusing on context issues in entrepreneurship education, but not having context as the dominant argument were classified as "Sectional". Literature with only minor or brief mention of context in entrepreneurship education was classified as "Minor". In total, 26 publications fell into the classification "Main focus" and thus were positioned as prioritized literature.

The second filter addressed the sociological phenomena levels - macro, meso and micro. These were also applied to the 26 "Main focus" publications in order to identify context elements. Macro represents national and international levels. Meso represents institutional (university) and regional levels. Micro represents individual and small group levels, as well as capturing more specific programme aspects.

In order to ensure a robust analysis, the remaining 206 publications ("Sectional" and "Minor") were analyzed for context elements using the same sociological phenomena levels. Three additional elements were identified, which are presented in the section Findings from 
non-"Main focus" literature. Throughout the reviewing process, the authors discussed classification to ensure consistency. As an additional consistency check, 50 randomly selected publications from the entire 232 population were reviewed and compared by multiple authors. Across the 50 publications, the authors were found to be consistent with one another in classification and analysis of context elements.

To understand how the contributions of the publications were developed, each publication was identified as either conceptual or empirical, with empirical sub-divided according to use of qualitative, quantitative or mixed-based methodology. The implications of the conceptual or empirical base of the reviewed publications are presented in Tables I and II with associated discussions. The 26 publications representing the prioritized literature, categorized into sociological levels with associated context elements, are listed in Table III.

The prioritized literature was then evaluated using a theoretical framework inspired by previous research (Goodman and Whetten, 1998; Jack and Anderson, 2002; Welter, 2011) to distil into: content (what), agency (who), positional (where) and temporal (when) aspects of context. The framework builds upon Welter (2011) emphasis of using context from an omnibus rather than discrete perspective, such that context is a lens through which entrepreneurship is investigated, rather than considered as a discrete variable. This perspective considers that positional and temporal aspects operate on various levels. To address this, the theoretical framework also incorporated the sociological phenomena levels of macro, meso and micro with additional sub-level distinctions.

\section{Findings from the literature review}

When examining who is framing the discussion of context in entrepreneurship education, one journal in particular, Education and Training, is dominant. Given its position relative to review of entrepreneurship education literature, it is not surprising that Education and Training is the dominant forum of the published work (33 of the 232 published works) addressing context in entrepreneurship education. The next 12 journals each published between three and nine articles (see Table AI). Discussion about context in entrepreneurship education did not commence until 1993. In comparison, context in entrepreneurship in general has been debated in journals since 1970, illustrating the difference in the maturity of the fields.

In the following, the findings from the literature review based on the Scopus search on "Entrepreneurship Education" and "Context" are presented.

\section{Context in entrepreneurship education}

There has been a steep increase of interest in the topic of context in relation to entrepreneurship education during the last 10 years, which is evidenced by increasing number of publications on the topic shown in Figure 1.

Context has been researched as both a primary focus and as a sub-theme using various methodological approaches. Table I illustrates the methodological approach distribution of all 232 publications. In total, 85 of these were conceptually based, and 145 were empirically based. The remaining two publications were identified as wide-ranging books. The empirical publications therefore represent the majority of the publications, and these were essentially evenly distributed as quantitative (69) and qualitative (67). Nine of the empirical publications applied mixed methods. No preferred methodology for researching context in entrepreneurship education is therefore evident.

From the 232 publications, 26 were classified as "Main focus" and thus considered the prioritized literature for the review. The prioritized literature provides a more complex and nuanced picture of context in entrepreneurship education. Similar to Table I the publications were organized according to their methodological approach. In addition, they were also organized at the sociological phenomena level, either as addressing one level in particular or 


\section{IJEBR}

Figure 1.

Number of

publications by year several levels (ex. micro + meso). Table II illustrates the distribution of the prioritized literature in terms of methodological approach and sociological phenomena level.

There is no discernible pattern when analyzing the methodology distribution and sociological phenomena level of the prioritized literature. In total, 9 of the 26 publications are conceptual; 17 are empirical, where quantitative (9) publications are the most common, followed by qualitative (5) and mixed method (3). In total, 16 publications address multiple levels while 10 publications focus on a single level. Only two of the publications address the micro level exclusively (and without any publications specifically addressing micro level quantitative, or separately micro level qualitative), with meso-level publications similarly uncommon (again with no qualitative methodology). Table II also explicates that it is most common to address context across all three levels and that this is not limited to any particular methodological approach.

Context elements are most commonly described as fixed explanatory factors: "the setting" of the entrepreneurship education or research. Context from this perspective is something entrepreneurship education and research is located in, not something that can be designed

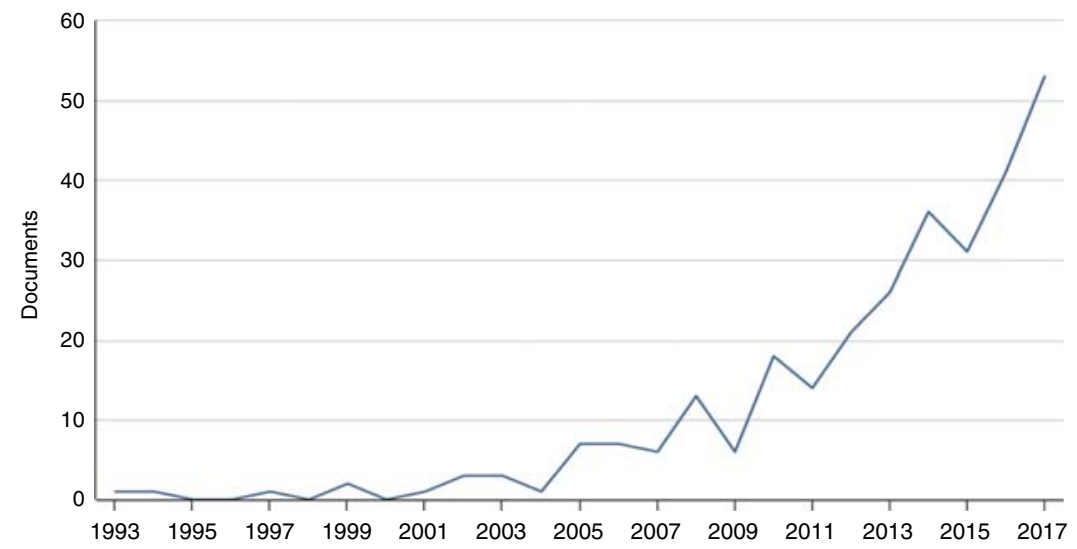

Publication type

Conceptual

Table I.

Distribution of publications based on methodological approach
Empirical, quantitative

Empirical, qualitative

Empirical, mixed method

Wide-ranging books

Total
Quantity of publications

85

69

67

9

2

232
Table II.

Distribution of prioritized publications based on context level and methodological approach

\begin{tabular}{lccccc}
\hline & \multicolumn{5}{c}{ Methodological approach } \\
Context level & Conceptual & Quantitative & Qualitative & Mixed method & Total \\
\hline Micro & 1 & & & 1 & 2 \\
Meso & 2 & 1 & & & 3 \\
Macro & 3 & 2 & 2 & 1 & 5 \\
Micro + Meso & 1 & 2 & 1 & & 4 \\
Meso + Macro & 1 & 4 & 2 & 1 & 4 \\
Micro + Meso + Macro & 1 & 9 & 5 & 3 & 26 \\
Total & 9 & & & &
\end{tabular}


with or in other ways utilized. While the literature states that context is important and Entrepreneurship influential in entrepreneurship education, context and context elements are either presented as documented items or using diffuse language which varies significantly between the education publications, thus giving an arbitrary understanding of what context is. To gain a cohesive understanding of what constitutes context in entrepreneurship education, more examination is needed to understand the pieces relative to one another. The following sections therefore present context elements from the prioritized literature. In Table III, context is addressed specifically in relation to three sociological phenomena levels: macro, meso and micro.

\begin{tabular}{|c|c|c|}
\hline Level & Context element & References \\
\hline \multirow[t]{8}{*}{ Macro } & Continent & Chauhan and Das (2016) and Giacomin et al. (2011) \\
\hline & Country & $\begin{array}{l}\text { Arokiasamy (2012), Balan-Vnuk et al. (2014), Blenker et al. (2008), } \\
\text { Chauhan and Das (2016), García-Rodríguez et al. (2017), Garavan et al. } \\
\text { (2010), Haddad et al. (2016), Johnson et al. (2006), Gerba (2012), Libombo } \\
\text { and Dinis (2015) and Mwasalwiba } \text { et al. (2014) }\end{array}$ \\
\hline & Government policy & $\begin{array}{l}\text { Anderson and Zhang (2015), Arokiasamy (2012), Balan-Vnuk et al. } \\
\text { (2014), Blenker et al. (2008),Garavan et al. (2010), Guerrero et al. (2014), } \\
\text { Lee et al. (2006), Libombo and Dinis (2015) and Mwasalwiba et al. (2014) }\end{array}$ \\
\hline & Economy & $\begin{array}{l}\text { Anderson and Zhang (2015), Balan-Vnuk et al. (2014), Chauhan and Das } \\
\text { (2016), Garavan } \text { et al. (2010), Giacomin et al. (2011) and Lee et al. (2006) }\end{array}$ \\
\hline & Labour market & Balan-Vnuk et al. (2014), Lee et al. (2006) and Mwasalwiba et al. (2014) \\
\hline & National culture and norms & $\begin{array}{l}\text { Anderson and Zhang (2015), Blenker et al. (2008), Chauhan and Das } \\
\text { (2016), Garavan et al. (2010), García-Rodríguez et al. (2017), Giacomin } \\
\text { et al. (2011) and Lee et al. (2006) }\end{array}$ \\
\hline & Globalization & Arokiasamy $(2012)$ \\
\hline & Technological development & Thestrup and Robinson (2016) \\
\hline \multirow[t]{4}{*}{ Meso } & Regional effects & $\begin{array}{l}\text { Anderson and Zhang (2015), Blenker et al. (2008), García-Rodríguez et al. } \\
\text { (2017), Leitch et al. (2012), Mars and Ginter (2012), Mwasalwiba et al. } \\
\text { (2014), Walter and Dohse (2012) and Walter et al. (2013) }\end{array}$ \\
\hline & University & $\begin{array}{l}\text { Anderson and Zhang (2015), Arokiasamy (2012), Blenker et al. (2008), } \\
\text { Garavan } \text { et al. (2010), García-Rodríguez et al. (2017), Gerba (2012), } \\
\text { Guerrero et al. (2014), Leitch et al. (2012), Mars and Ginter (2012), } \\
\text { Mwasalwiba } \text { et al. (2014), Walter } \text { et al. (2010) and Walter } \text { et al. (2013) }\end{array}$ \\
\hline & Discipline & $\begin{array}{l}\text { Johnson et al. (2006), Maritz and Brown (2013), Neumeyer and Mckenna } \\
\text { (2016) and Thestrup and Robinson (2016) }\end{array}$ \\
\hline & Digital tools & Thestrup and Robinson (2016) \\
\hline \multirow[t]{8}{*}{ Micro } & Pedagogy and didactics & $\begin{array}{l}\text { Blenker et al. (2008), Chauhan and Das (2016), Fayolle and Toutain } \\
\text { (2013), Garavan et al. (2010), Haddad et al. (2016), Johnson et al. (2006), } \\
\text { Lee et al. (2006), Libombo and Dinis (2015), Maritz and Brown (2013), } \\
\text { Neumeyer and McKenna (2016), Walter and Dohse (2012) and Xie and } \\
\text { Wang (2014) }\end{array}$ \\
\hline & Assessment & Maritz and Brown (2013) \\
\hline & Students & $\begin{array}{l}\text { Blenker et al. (2008), García-Rodríguez et al. (2017), Fayolle and Toutain } \\
\text { (2013), Giacomin et al. (2011), Guerrero et al. (2014), Haddad et al. (2016), } \\
\text { Lee et al. (2006), Leitch et al. (2012), Maritz and Brown (2013), Neumeyer } \\
\text { and Mckenna (2016), Obrecht (2016), Walter et al. (2010) and Xie and } \\
\text { Wang (2014) }\end{array}$ \\
\hline & Educators & $\begin{array}{l}\text { Garavan et al. (2010), Giacomin et al. (2011), Maritz and Brown (2013) and } \\
\text { Libombo and Dinis (2015) }\end{array}$ \\
\hline & Stakeholders and network & Libombo and Dinis (2015) and Neumeyer and McKenna (2016) \\
\hline & Online setting & Thestrup and Robinson (2016) \\
\hline & Learning space & Haddad et al. (2016) \\
\hline & Content & $\begin{array}{l}\text { Blenker et al. (2008), Fayolle, and Toutain (2013), Garavan et al. (2010), } \\
\text { Gerba (2012), Johnson et al. (2006), Libombo and Dinis (2015), Maritz and } \\
\text { Brown (2013) and Xie and Wang (2014) }\end{array}$ \\
\hline
\end{tabular}

Table III. Context elements arranged by level 
Macro level

On the macro level, ten context elements are identified, as illustrated in Table III. Geography is often used to explain a contextual setting. For example, using data from Belgium, USA, China, India and Spain, Giacomin et al. (2011) find that there are common factors of motivation towards entrepreneurship, such as status, desire for independence and personal development, but that the entrepreneurial intention of students is influenced by their country/cultural background. Comparing political and economic perspectives from Europe, the Middle East, North America and India, Chauhan and Das (2016) investigate the entrepreneurship activity of the population and differentiating factors driving entrepreneurship education and training. Country setting is also widely used as an explanatory factor that implicitly or explicitly accounts for a number of other context elements such as: government policy, national economy, labour market conditions, national culture and norms.

Government policy is indeed an influential context element. Policy can promote entrepreneurship and entrepreneurship education through positive attention and resource allocation, or serve as a barrier through complicated legislation, rigid bureaucracy and underfunding. In their comparative study of the USA, Fiji, South Korea and China, Lee et al. (2006) discuss how government promotion is an important influencing factor on students' attitude towards entrepreneurship, while in Mozambique, underfunding was shown to be a main barrier to effective entrepreneurship education (Libombo and Dinis, 2015). Government policy is seen as influential through institutional economy (Guerrero et al., 2014), which can amplify or hinder entrepreneurship education, including preconditions. Similarly Anderson and Zhang (2015) illustrate the differences in attention to entrepreneurship education support based on embeddedness in a prioritized (or not) region within a socialist market economy. Mwasalwiba et al. (2014) investigate the role entrepreneurship education plays in the economic transition of Tanzania and the associated influence and effects of policy and labour market. Balan-Vnuk et al. (2014) advocate entrepreneurship education as critical in policy making in Sri Lanka for inspiring sole proprietorship and desire to promote self-sustained citizens. Garavan et al. (2010) emphasize government policy as one of five dimensions influencing entrepreneurship education in Ireland. Today this is a promoting factor, but in 1932 Ireland the policy of protectionism was not conductive to the emergence of new venture creation, and arguably resulted in the distortion of the economy.

National economic situation linked to policy is another context element discussed in the prioritized literature (Anderson and Zhang, 2015; Chauhan and Das, 2016; Giacomin et al., 2011; Lee et al., 2006). The setting of entrepreneurship education in developing countries can serve as both a barrier and a promoter for entrepreneurship and by extension entrepreneurship education. Funding can be difficult to obtain but a poor economy can serve as a motivational factor and catalyze necessity-driven entrepreneurship (Balan-Vnuk et al., 2014), as a restricted financial situation is shown to increase student motivation and entrepreneurial intention, thus advocating entrepreneurship education policy at a national scale. Garavan et al. (2010) categorize economy as a second dimension that shapes entrepreneurship education by affecting national policy.

Labour market conditions seem to influence student's motivation for entrepreneurship, as high levels of unemployment can be a strong inspirational and motivational factor for entrepreneurship education. This associates to both economic and government policy themes. Lee et al. (2006) found that necessity increases entrepreneurial intent while ease of obtaining employment decreases entrepreneurial intent. This finding is echoed in BalanVnuk et al. (2014) and Mwasalwiba et al. (2014) where entrepreneurship education is argued to promote self-employment.

National culture and norms, while less tangible, emerge numerous times in the prioritized literature. National values and the social and cultural environment of countries are found to influence entrepreneurship education (Anderson and Zhang, 2015; Chauhan and Das, 2016; 
García-Rodríguez et al., 2017). National culture is found to explain differences in Entrepreneurship entrepreneurial intention of students, even when common motivational factors (pursuit of profit/social status, desire for independence, creation, personal development and professional education dissatisfaction) align across countries (Giacomin et al., 2011). Others discuss the importance of social acceptance in regards to entrepreneurial culture (Chauhan and Das, 2016; García-Rodríguez et al., 2017), as lack of social acceptance and low practical ability has a negative effect on students' attitudes towards entrepreneurship (Lee et al., 2006). Cultural dimensions, such as low power distance, weak uncertainty avoidance, masculinity and individual achievement, are seen to promote entrepreneurial action (Hofstede, 2001). Several pieces of literature illustrate overarching cultural differences shaping the whole educational system, including attitude towards entrepreneurship (Blenker et al., 2008; Garavan et al., 2010; García-Rodríguez et al., 2017; Gerba, 2012; Leitch et al., 2012). Blenker et al. (2008) contrast wage-earner culture to entrepreneurial culture and argue for the importance of institutional fit to intended culture development. And while Garavan et al. (2010) emphasize the agricultural traditions in rural Ireland impacting entrepreneurial attitudes, it is recognized that national culture may have diminishing significance due to emerging globalization.

Globalization and technical development trends are mentioned as macro-level context elements that influence entrepreneurship education. Arokiasamy (2012) investigates globalization trends as mediated through government policy, and Thestrup and Robinson (2016) showcase how advances in digitalization enable a new global connectivity and scaffolding methods transcending all levels of context.

\section{Meso level}

In total, 16 publications are found to include context elements on the meso level, further sub-divided into regional effects, university specific elements and disciplinary effects. Similar to the macro level, governance and economy are key themes at the meso level, but these are now positioned within the region and institution. Culture and norms are also confined to the institutional sphere at the meso level. Activities, actors and networks are found more prominently at the meso level.

Regional effects, such as innovative activities, regional economy, and, by extension, investment in research development and innovation, affect the entrepreneurial intention of the regional population. Walter and Dohse (2012) illustrate the degree of entrepreneurial activity within a region can affect entrepreneurial learning, but that this is dependent on the mode of education. Active modes of education are, irrespective of the regional context, positively related to self-employment intentions, whereas reflective modes of education raise self-employment intentions only in regions with a high degree of entrepreneurial activity. The positive effect on entrepreneurial learning happens between the individual and the local context, emphasizing the importance of embeddedness in active and innovative regions. Interstitial organizations, specially run units at community colleges connecting academics with private organizations such as incubators, are shown to play an important role in developing entrepreneurial capacity in the regional workforce (Mars and Ginter, 2012). Blenker et al. (2008) call attention to general institutional (university) strategy in relation to entrepreneurial activities in the regional environment and its importance for entrepreneurship education, thus positioning the university as a key contextual element in itself.

University-specific context is the most prominent element at the meso level and is influenced by elements also found at the macro level; namely, governance and economy. Government policy is a strong governing mechanism in terms of educational funding and objective. Universities in Malaysia benefit from government policy actively promoting entrepreneurship education spurred by the trend of globalization (Arokiasamy, 2012). Universities are similarly affected by the regional governance and institutional economy. 
Guerrero et al. (2014) argued that entrepreneurial universities either have or are positioned to develop innovative pathways to reinforce entrepreneurship in their region; or alternatively suffer from lack of government support to prioritize resources to their region, given institutional rank (Anderson and Zhang, 2015). Additionally, university policy including institutional governance and leadership, organizational culture, strategy and purpose, and institutions' approaches to the commercialization of research and technology relating to the university and programme context (Garavan et al., 2010) are all influential context elements framing entrepreneurship education. Universities need to focus on entrepreneurship educational design, in order to stimulate self-employment post university (Mwasalwiba et al., 2014) as entrepreneurship education, entrepreneurship support programmes and industry ties are all found to have positive effect on student intention of self-employment (Walter et al., 2013). Blenker et al. (2008) found that university age, history, management, identity and norms are highly influential, as are networks with other universities and between faculties within the university itself, as these develop and promote entrepreneurship education and support student extracurricular activity, for example, via incubators.

Programme/disciplinary setting - like geography, disciplinary setting is often used as an explanatory setting. Culture and norms are not only set by the university, they can be further divided into discipline specific sub-cultures. García-Rodríguez et al. (2017) found that university environment inclusive of normative and cognitive development, directly influences students' attitudes, self-confidence and motivation, and through these can affect entrepreneurial intention (Blenker et al., 2008). Garavan et al. (2010), Maritz and Brown (2013) and Johnson et al. (2006) all argue for a discipline-based framework for developing entrepreneurial competence, in terms of profession-, industry- or invention-based entrepreneurial ventures. For example, in a developmental economy such as Tanzania (Gerba, 2012), entrepreneurship education is mainly situated in certain disciplines, such as business and agriculture, but this is reflected in the trajectory of entrepreneurship education development in more established economies, such as the USA (Solomon, 2007). Current policy (Bacigalupo et al., 2016) and research (Kuratko and Morris, 2018) argue for application of entrepreneurship to all disciplines, which, in turn, create a need for development of academic staff. This leads to the micro-level context elements.

\section{Micro level}

At the micro level, eight context elements are identified, with the primary unit of study being actors and interactions. Not surprisingly pedagogy and didactics are central themes in half of the publications. The purpose or objective of the entrepreneurship education spans from promoting new venture creation to stimulating enterprising behaviour in general (Blenker et al., 2008; Maritz and Brown, 2013). Choice of objective greatly influences the applied pedagogy, didactics and content of any given course (Maritz and Brown, 2013; Neumeyer and McKenna, 2016). Applied pedagogy spans learning methods, models, approach and didactics (Blenker et al., 2008; Chauhan and Das, 2016; Maritz and Brown, 2013; Walter and Dohse, 2012), and while more advanced means, such as experiential learning and reflexivity are advocated, they are also recognized as challenging to design and deliver, calling attention to issues of assessment (Maritz and Brown, 2013). Integrating these issues, Maritz and Brown (2013) argue for adapting Alberti et al.'s (2004) model to entrepreneurship education programmes in order to holistically assess the why (objectives), what (content), how (pedagogy) and for whom (audiences) in entrepreneurship education.

Because learning is socially situated (Lave, 2009) the actors involved in the learning process, the students, the educators, external stakeholders and social network, all carry significance. Student-related context elements are extensive, including nationality, 
cultural heritage and professional profile (Giacomin et al., 2011), preferred learning style Entrepreneurship (Walter et al., 2010) and gender (Giacomin et al., 2011; Haddad et al., 2016; Maritz and Brown, 2013). Haddad et al. (2016) question the extent to which education accounts for gender stereotypes and how this is or could be counteracted, through entrepreneurial self-efficacy. Cultural heritage, gender and field of study all influence student entrepreneurial intention, disposition and sensitivity to motivation and perceived barriers for entrepreneurship (Giacomin et al., 2011), all of which feeds back to determining how to design entrepreneurship education to maximize learning outcome for the involved individuals.

Many context elements at the micro level originate outside the classroom but are carried into the classroom by the students (Obrecht, 2016). García-Rodríguez et al. (2017) found that the social context, including family, exerts a weak direct influence on the perceived attitudes or desire towards the option to start a business, and an indirect influence on entrepreneurial intention. For example, Xie and Wang (2014) emphasized individually based social and emotional aspects of learning contributing to educational objectives, and others highlight individual competence (Maritz and Brown, 2013) and social network (Walter et al., 2010) as capital that students bring into the entrepreneurial learning process. These context elements play a role in relation to entrepreneurship education and are found to affect entrepreneurial intent (García-Rodríguez et al., 2017), perception of entrepreneurial capacity (Haddad et al., 2016) and entrepreneurial action (Guerrero et al., 2014). The diversity of the student body (Maritz and Brown, 2013) also affects the outcome in an entrepreneurial learning process. Heterogeneity can spark creativity but also present itself as a barrier for collaboration. Taken together, these context elements make it difficult to generalize best practice without taking actor preferences and preconditions into account, and this can expand from an individual, to a team or interpersonal focus as well (Neumeyer and McKenna, 2016).

Not only are students important contextual carriers, but educators are as well. Maritz and Brown (2013) acknowledge an educator's knowledge, skill and attitude as influential to receipt of entrepreneurship education. Garavan et al. (2010) problematize educators' lack of experience while at the same time illustrates challenges faced when linked to both universities and businesses. In addition, Libombo and Dinis (2015) discuss challenges around pedagogic design and content and identify main barriers as lack of resources, qualified teachers and networks. Other external stakeholders, i.e. local business counsellors, entrepreneurs, funding agencies and potential customers are also included as influential actors in relation to entrepreneurship education (Neumeyer and McKenna, 2016).

The micro contextual setting is addressed as a learning space (Haddad et al., 2016) but it also includes online opportunities, such as educating through blended learning (Chauhan and Das, 2016; Haddad et al., 2016; Thestrup and Robinson, 2016). The final context element drawn from the literature at the micro level is content (of courses, syllabus/curriculum). Content is central in entrepreneurship education (Garavan et al., 2010; Johnson et al., 2006; Maritz and Brown, 2013) and is addressed by approximately one-third of the prioritized literature. Content is directly associated to the purpose of the education as it is the baseline provision to support the learning objectives, as exemplified in the Blenker et al. (2008) framework for developing entrepreneurship education.

\section{Cross-level observations}

Central themes across sociological phenomena levels include political and economic influences, geography, culture and development, activities, networks, actors and interactions. Transitioning from the macro to the micro level shifts focus from general policy to actors and interactions. Culture is a transcending theme across national culture at 
the macro level, institutional culture at the meso level and individual culture at the micro level. A relatively new context element recognized on all levels is digitalization (Thestrup and Robinson, 2016).

\section{Additional context elements from non-"Main focus" publications}

Analysis of literature in all three classifications ("Main", "Sectional" and "Minor") presents a broad geographical spread, with 5 regions and 36 countries acting as "the setting" of the entrepreneurship education (see Table AII). To ensure that no context elements were missed, the analysis of the original 232 publications was revisited to scan for additional elements that were discussed in publications with "Sectional focus on context issues in entrepreneurship education" or "Brief mentioning of context in entrepreneurship education". Three additional elements were identified.

Relating to the micro level, pedagogy and setting, simulation and gaming (Newbery et al., 2016; Pavlova and Chernobuk, 2016) were considered as the extension to scaffolding methods, enabling the educator to mediate entrepreneurial experience through a controlled process. Relating to focus in content and setting, Pittaway and Thorpe (2012) introduce temporal business phases - pre-start-up, start-up, growth, crisis and failure - to contextualization. Type of start-up is also presented as a contextual setting (Zhang, 2015), with family businesses positioned as having particular context elements as a type of startup (Barrett, 2014; Rautamäki and Römer-Paakkanen, 2016).

Not adding new levels or elements, five publications complimented the discipline setting by elaborating upon which industry "one" is educated for and in such as public sector (Adcroft et al., 2005), creative industries (Carey and Matlay, 2010), engineering (Thongpravati et al., 2016) or music (Noyes and Deligiannidis, 2012).

\section{Benefits and challenges with integrating context in entrepreneurship education}

At all levels, context elements can either limit or enable entrepreneurial activities, entrepreneurial opportunities and motivation for becoming entrepreneurial (Welter, 2011), all essentially influencing the prerequisites for entrepreneurship education. Preconceptions of purpose, process and definitions are all shaped by context (Zahra et al., 2014). Most educational designs are tailored by educators to move the students towards the educators' preconceptions, but if the gap between the preconceptions of the educator and his or her students is too large, it will be a very difficult task, and a challenging journey for the students to take (if they even are open to doing so) (Seikkula-Leino et al., 2010; Williams Middleton and Donnellon, 2014).

In relation to limiting or enabling students in entrepreneurship educational processes, many context elements come into play. The students' background (Fayolle and Gailly, 2008; Walter et al., 2010) can hold inspiration or necessity for entrepreneurial action, or on the contrary, cause reluctance to engage in entrepreneurial action. Both family (García-Rodríguez et al., 2017) and cultural background (Giacomin et al., 2011) can also have an influence on entrepreneurial intent. Moreover, social network (Walter et al., 2010) can be essential in enabling entrepreneurship giving access to resources, but reference groups can also have a negative influence on entrepreneurial attitude if entrepreneurial action goes outside the social norms. In the course setting, the fit between student's preferred learning style (Walter and Dohse, 2012) and the pedagogy and didactics applied in the course is important in relation to the learning process. Furthermore in the professional profile of the education (Giacomin et al., 2011) there can be an necessity for entrepreneurial action related to future employment, which can also be related to general labour market conditions (Lee et al., 2006). 
For educators many context elements influence the design process and the execution of Entrepreneurship entrepreneurial educational processes. However, far from all context elements are within the educator's span of control and some may even be difficult to predict. Indeed, contextualizing entrepreneurship education calls for an individualistic approach because there is no ceteris paribus in entrepreneurship education. At a programme and university level, resources allocated to individual courses, student number, scheduling flexibility and requirements for assessment (Maritz and Brown, 2013) can have a great influence on applied pedagogy and didactical design opportunities (Blenker et al., 2008; Chauhan and Das, 2016; Maritz and Brown, 2013; Walter and Dohse, 2012). University culture and traditions can either support or hinder entrepreneurial activities (Blenker et al., 2008). Similarly, regional effects can also have a supportive or limiting impact on entrepreneurship activities, as some regions provide strong support and resources for entrepreneurial activities enabling inclusion of various stakeholders (Neumeyer and McKenna, 2016), i.e. local business counsellors, entrepreneurs, funding agencies and potential customers; while others deprioritize one region or university for another (Anderson and Zhang, 2015). Finally, educator network, knowledge, skills and attitudes (Maritz and Brown, 2013) influence the educational process, and much like the students, the educator's background can either enable or limit the entrepreneurial education process.

Welter (2011) and Zahra et al. (2014) identify temporal settings as an important part of context. However, research in entrepreneurship, and additionally entrepreneurship education, has not fully accounted for the interdependency of temporal and other dimensions of context (Zahra et al., 2014), and the potential influence on context elements, such as policy and economies in transition (Libombo and Dinis, 2015; Mwasalwiba et al., 2014). As evidenced by this review, accounting for temporal settings while embedded in them continues to be a key challenge in entrepreneurship research, but the benefit of increasing awareness of this dimension may provide insight into trends and transitions experienced in relation to other context elements.

\section{Discussion}

Drawing from the findings of the literature review, we put forth four main assertions: context in entrepreneurship education is arbitrary; context in entrepreneurship education is both documented and diffuse; educators have a limited span of control in relation to context elements; a lack of ceteris paribus in entrepreneurship education.

Context is everywhere and no-where. There is no general framework for working with context in in entrepreneurship education, nor is there existing research that covers all levels and context elements simultaneously. Instead context in entrepreneurship education literature is currently scoped to the interest or expertise of the author(s), scoped by the frame or audience of the publication outlet, or limited by the explanatory ability of the empirics. To comprehensively cover context at all levels would demand large and coordinated efforts, with access to proprietary and/or sensitive information and may be outside current means. Our findings, consistent with previous research (e.g. Zahra et al., 2014), also find that context is inherently tensioned, which could limit the level of prescription a framework could provide.

Entrepreneurship education, including context elements, is increasingly documented and empirically investigated through multiple forms of policy, analysis, funding description, university and programme framing and accreditation and university network peer evaluation, applied pedagogy and didactics, content, etc. This is evidenced through the everincreasing publication of entrepreneurship education research, introduction of new entrepreneurship education conferences and journals, and government programmes, papers and reports. At the same time, entrepreneurship education research is still predominantly descriptive, building upon cases and storytelling (Johannisson, 2016) because of the complex matrix of variables that shape the learning experience, which, to be 
entrepreneurial, is fundamentally situated relative to uncertainty. There are even attempts to document the contextual influence of culture (Giacomin et al., 2011; Lee et al., 2006), but social interactions, personal heritage and preference are still diffuse, while at the same time highly influential context elements.

With the increasing complexity of education and the educator's span of control in relation to context elements is further limited. Developments of online learning, MOOCs, flipped classroom, etc. mean that the learning space is no longer confined and thus ability to control and stabilize influential variables is reduced (Lackéus and Williams Middleton, 2018). At the same time, there are often clear guidelines in terms of time, credit points, learning objectives, physical interactions, etc. that allow the educator to define and make decisions upon what and how is taught and with whom the students interact. This perhaps indicates a shift from an educator's responsibility of distributing knowledge and what to think, to educators as facilitators of tools to think with - tools that frame learning and sensemaking.

These insights lead to the conclusion that there is no real ceteris paribus in entrepreneurship education. Recognizing that context matters are accepting that everything else is not equal. The importance of context in entrepreneurship education is well established, but, as has been shown, context has rarely been the central focus but has rather been addressed as an influencing element, and thus context elements have not been systematically transferred into research addressing how educators can actively design with context in mind. As Welter et al. (2016) argue, a contextualized understanding questions our tendency for an "all-are-alike" approach. Thus, while context creates a generalization dilemma, we can generalize how we frame context through elements (Table III) and a conceptual framework (Table IV). If we approach context from two perspectives, as a lens (omnibus) and as a (discrete) variable (Welter, 2011), we argue that educators can make better educational designs by raising their contextual awareness, understanding of which context elements can be designed with or otherwise influenced proactively, and which context elements are those to which educational design must adhere. Educators therefore need to make sense of the "who, what, where and when" (Welter, 2011) of context to strengthen the student's learning process in entrepreneurship education. Next, we use findings from the literature review and identified context elements to present a conceptual framework.

\section{Making sense of context in entrepreneurship education}

To operationalize context in relation to entrepreneurship education, Table IV provides questions for educators interested in designing with context when developing their learning processes. Some context elements will be within the educator's span of control and can therefore be applied directly into the educational design and delivery. Other context elements are outside the span of control and may therefore constitute "framing factors" to which educators must adhere, adapt or slowly adjust over time. In either case, part of the educator's role in entrepreneurship education is as a mediator of context for the students in their learning process.

Table IV presents context elements at the macro, meso and micro levels, with additional level distinction stemming from the prominent themes identified through the literature analysis. The macro level is divided into a national and international level, as policy and economics associated to education are often governed through national and international guidelines. The meso level is constituted by the programme and university as institutional contexts and the local regional context. The micro level is the course level, the classroom. The questions asked at the different levels are relating to the context elements of who, what, where and when.

As Table IV suggests, working with "who" at all levels will help identify relevant stakeholders and gatekeepers. In the literature this is mostly discussed at the micro level, where students (Blenker et al., 2008; García-Rodríguez et al., 2017; Giacomin et al., 2011; 


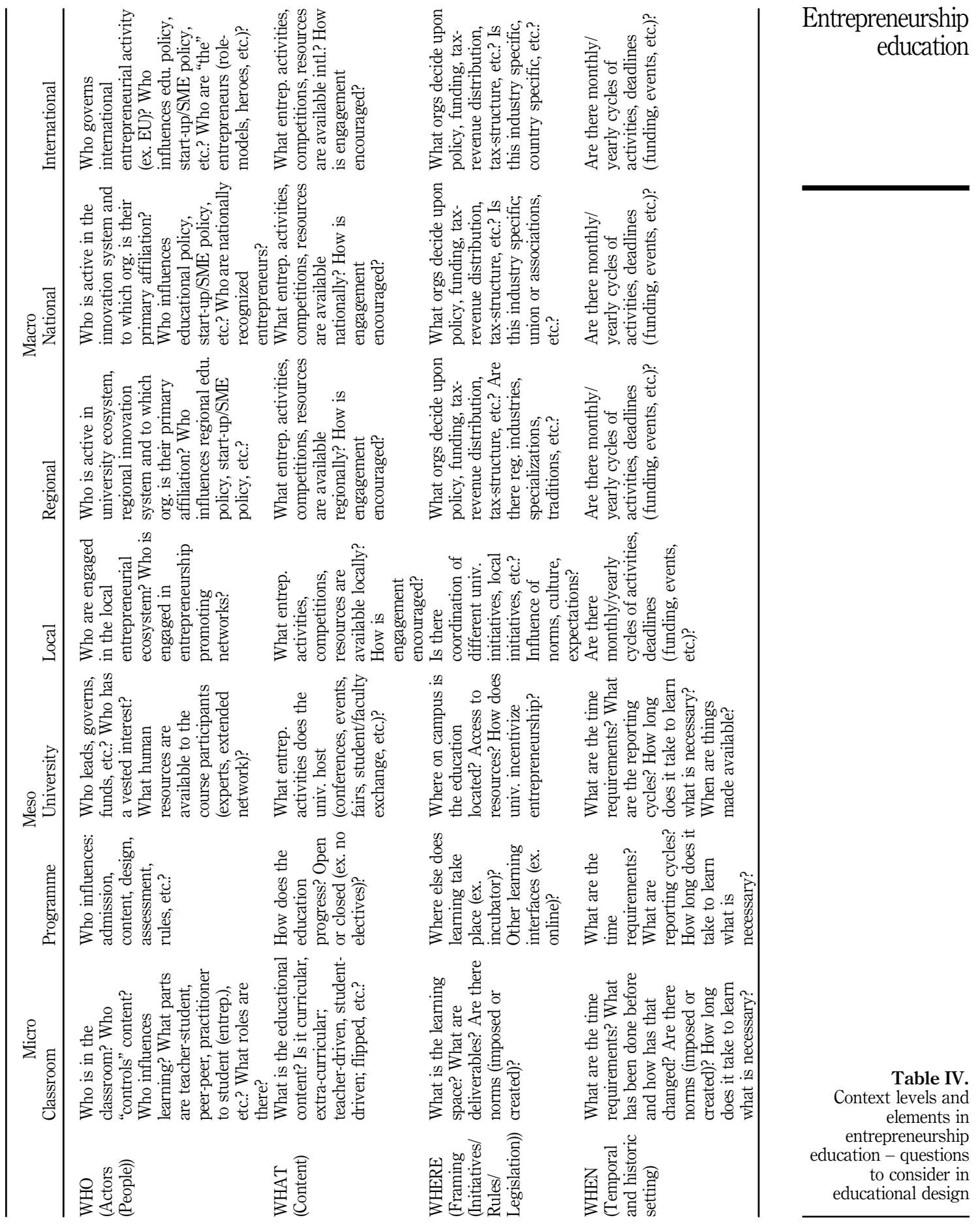



et al., 2010), educators (Maritz and Brown, 2013) and related stakeholders (Neumeyer and McKenna, 2016) are presented as key actors. Understanding the "who" can enable expedient networking, while also promoting awareness and understanding of the potentially complex mix of actors, with diverse cultural heritages, involved in an entrepreneurial learning process. Such an understanding may support successful interaction.

It may seem obvious, but the "what" simply concerns the capture and presentation of descriptive phenomena in relation to entrepreneurship education, at all levels. This facilitates understanding in regard to activities, content, resources and process, in order to guide actors involved in terms of what they can participate in and what they need to do.

Much of the literature identifies "where" as a setting and explanatory factor their research and findings. The "where" on the macro level is the country specific context (Blenker et al., 2008; Garavan et al., 2010; García-Rodríguez et al., 2017; Gerba, 2012; Leitch et al., 2012), that uses explanatory factors as political governance (Anderson and Zhang, 2015; Balan-Vnuk et al., 2014; Blenker et al., 2008; Guerrero et al., 2014; Lee et al., 2006; Mwasalwiba et al., 2014), economy (Anderson and Zhang, 2015; Balan-Vnuk et al., 2014; Blenker et al., 2008; Guerrero et al., 2014; Lee et al., 2006; Mwasalwiba et al., 2014) and culture (Anderson and Zhang, 2015; Blenker et al., 2008; Chauhan and Das, 2016; Garavan et al., 2010; García-Rodríguez et al., 2017; Lee et al., 2006) to describe the entrepreneurial environment. At the meso level the university setting is primarily described as an influential context element (Arokiasamy, 2012; Blenker et al., 2008; García-Rodríguez et al., 2017; Gerba, 2012; Guerrero et al., 2014; Haddad et al., 2016; Mars and Ginter, 2012; Walter and Dohse, 2012; Walter et al., 2013). The "where" is most often described as a setting, providing frames that either hamper or promote entrepreneurship education and as something educators must navigate within.

Finally, the "when" of context is understood as the period in which the entrepreneurship education takes place, but also the frequency and longevity of the education. This dimension is not significantly described in the literature, but rather related to the political and economic themes in terms of, for example, the timeframe of a transitional economy (Lee et al., 2006). However, it may be quite important in terms of deciding when we should teach whom what, as one size does not fit all (Blenker et al., 2012).

Not all context elements may be relevant to consider for every educational design. Some elements can be proactively designed by the educator, while other elements are out of the span of control and must be considered as fixed framing elements that the educator reactively adheres to, with potential to perhaps change over time, depending upon institutional or other legitimizing support.

\section{Conclusions and implications}

In this paper, a systematic literature review was conducted to answer the question: "what constitutes context in entrepreneurship education?" Analysis found that context in entrepreneurship education can be described at multiple levels and be categorized in relation to multiple elements. As suggested in in Table III, context elements can be identified across three levels, macro, meso and micro. These findings align with previous research addressing context in entrepreneurship literature in general (Welter, 2011). More specifically, key themes were identified which prioritized context elements at the different levels, such as country/national description at the macro level, university at the meso level and student/student activities at the micro level. Given that context is a complex phenomenon, structuring the perspective through sociological phenomena levels and in relation to the "who, what, where and when" frame enables researchers and practitioners to better identify and address the constituting elements.

To address the $R Q 2$ context elements were framed with the categorization of content (what), agency (who), positional (where) and temporal (when) distilled from established frameworks (Goodman and Whetten, 1998; Jack and Anderson, 2002; Welter, 2011) and resulting in 
Table IV. The framework provides educators with questions to guide the designing of Entrepreneurship education with context. While this framework illustrates ways in which context can influence or is influenced by entrepreneurship in an educational setting, not all elements will be relevant for every educational design, and it is yet to be empirically tested. Nonetheless, the analysis and resulting framework emphasizes the importance of consciously working with context elements in relation to educational design, providing options for proactive rather than reactive engagement. This enables educators and students to better become "pilots" (Sarasvathy and Dew, 2005) in their learning and entrepreneurial processes, such that they can better identify, understand and use the context elements from and in their educational setting.

The practical implication is a guideline for design of entrepreneurship education programmes and courses that take context elements into consideration. This includes awareness of applicability of certain context elements to education approaches. Some elements may align naturally with a "learning through" approach (Neck and Greene, 2011; Ollila and WilliamsMiddleton, 2011; Pittaway and Thorpe, 2012), just as "learning about" naturally limits contextual richness, but may be allows for macro level perspectives (what is entrepreneurship in economics, what is entrepreneurship in sociology and what impact do national and international markets have on entrepreneurship, historically and currently), etc. These may be definitional elements in "about", whereas they are more experiential elements in the "in" or "through".

Entrepreneurship education is a global phenomenon (see Table AII), recognized by governments practitioners alike for its importance in contributing to growth and value creation (Kaufmann, 2009). Entrepreneurship education is gaining increased scholarly attention (Nabi et al., 2017) and is still emerging in many regions, as exemplified by Figure 1. This signals the importance of introducing a framework for defining and working with context in entrepreneurship education, to support comparative analysis and continued research development.

A key aim of the paper has been to increase insight and awareness regarding potential knowledge gaps between the entrepreneurial experience, as addressed in general entrepreneurship literature, and the use of different types of education to inspire and prepare students for entrepreneurial practice, or to learn more about entrepreneurship. However, there are still several unanswered questions regarding context in entrepreneurship education, which need to be put on the entrepreneurship education research agenda: what are common means for designing with context? And to what extent are micro and meso context elements driven by macro level elements? As the current dialogue about context in entrepreneurship education was shown to be limited to predominantly one journal, a broader exposure would enrich the research in this field. Qualifying contextualization of entrepreneurship education in research enables a shift from arbitrary single case studies towards an understanding of how to generalize when taking context into account. This positions entrepreneurship educators as a key audience for this work, but there are additional practitioners to consider: university leaders, educators in other disciplines, collaboration partners or acting entrepreneurs that are engaged in the learning spaces.

We have aimed to call attention to the importance of context in entrepreneurship education. Table III provides a tool to decipher how context has been treated in entrepreneurship education theory and through the three levels of categorization making it more navigable. In extension, the benefits and challenges with integrating context in entrepreneurship education are addressed. With Table IV, educators are given a framework to make sense of their specific context. The framework provides a holistic view of context and educators are then left with the choice of which context elements are relevant for them to design with. Next steps include determining means to test and validate the framework. The "interactive" structure is intended to provide more descriptive rather than definitional framing. Over time, qualification and meta-analysis from the research community as well as practitioners in the field is required to gain and validate additional insights. 


\section{References}

Adcroft, A., Dhaliwal, S. and Willis, R. (2005), "Insatiable demand or academic supply: the intellectual context of entrepreneurship education”, European Business Review, Vol. 17 No. 6, pp. 518-531.

Alberti, F., Sciascia, S. and Poli, A. (2004), "Entrepreneurship education: notes on an ongoing debate", 14th Annual IntEnt Conference, Naples, 4-7 July.

Anderson, A.R. and Zhang, X. (2015), "Enterprise education with Chinese characteristics; policy, practices and uneven development in PRC", Journal of Entrepreneurship in Emerging Economies, Vol. 7 No. 3, pp. 276-292.

Arokiasamy, A.R.A. (2012), "The influence of globalization in promoting entrepreneurship in Malaysia”, South East European Journal of Economics and Business, Vol. 7 No. 2, pp. 149-157.

Autio, E., Kenney, M., Mustar, P., Siegel, D. and Wright, M. (2014), "Entrepreneurial innovation: the importance of context", Research Policy, Vol. 43 No. 7, pp. 1097-1108.

Bacigalupo, M., Kampylis, P., Punie, Y. and Van Den Brande, G. (2016), EntreComp: The Entrepreneurship Competence Framework, JRC European Commission, Luxembourg.

Balan-Vnuk, E., Dissanyake, M. and O'connor, A. (2014), "Policy analysis for entrepreneurship education in necessity-based contexts: a Sri Lankan case study", in Brewer, J. and Gibson, S.W. (Eds), Necessity Entrepreneurs: Microenterprise Education and Economic Development, Edward Elgar, Cheltenham, pp. 160-182.

Barab, S.A. and Plucker, J.A. (2002), "Smart people or smart contexts? Cognition, ability, and talent development in an age of situated approaches to knowing and learning", Educational Psychologist, Vol. 37 No. 3, pp. 165-182.

Barrett, M. (2014), "Revisiting women's entrepreneurship: Insights from the family-firm context and radical subjectivist economics", International Journal of Gender and Entrepreneurship, Vol. 6 No. 3, pp. 231-254.

Blenker, P., Dreisler, P., Færgemann, M.H. and Kjeldsen, J. (2008), “A framework for developing entrepreneurship education in a university context", International Journal of Entrepreneurship and Small Business, Vol. 5 No. 1, pp. 45-63.

Blenker, P., Trolle Elmholdt, S., Hedeboe Frederiksen, S., Korsgaard, S. and Wagner, K. (2014), "Methods in entrepreneurship education research: a review and integrative framework", Education + Training, Vol. 56 Nos 8-9, pp. 697-715.

Blenker, P., Frederiksen, S.H., Korsgaard, S., Müller, S., Neergaard, H. and Thrane, C. (2012), "Entrepreneurship as everyday practice: towards a personalized pedagogy of enterprise education", Industry and Higher Education, Vol. 26 No. 6, pp. 417-430.

Carey, C. and Matlay, H. (2010), "Creative disciplines education: a model for assessing ideas in entrepreneurship education?”, Education and Training, Vol. 52 No. 8, pp. 694-709.

Chauhan, R.S. and Das, R. (2016), "Review of entrepreneurship education in Europe, Middle East, North American countries compared to India", in Erdoğdu, M. and Christiansen, B. (Eds), Comparative Political and Economic Perspectives on the MENA Region, IGI Global, Hershey, PA, pp. 306-319.

Cope, J. (2005), "Toward a dynamic learning perspective of entrepreneurship", Entrepreneurship Theory and Practice, Vol. 29 No. 4, pp. 373-397.

Fayolle, A. and Toutain, O. (2013), "Four educational principles to rethink ethically entrepreneurship education", Revista de Economia Mundial, pp. 165-176.

Fayolle, A. and Gailly, B. (2008), "From craft to science: teaching models and learning processes in entrepreneurship education”, Journal of European Industrial Training, Vol. 32 No. 7, pp. 569-593.

Garavan, T., Birdthistle, N., Ó Cinnéide, B. and Collet, C. (2010), "Entrepreneurship education in the republic of Ireland: context, opportunities and challenges", in Fayolle, A. (Ed.), Handbook of Research in Entrepreneurship Education, Volume 3: International Perspectives, Edward Elgar Publishing, Cheltenham, pp. 225-247. 
García-Rodríguez, F.J., Gil-Soto, E., Ruiz-Rosa, I. and Gutiérrez-Taño, D. (2017), "Entrepreneurial Entrepreneurship potential in less innovative regions: the impact of social and cultural environment", European Journal of Management and Business Economics, Vol. 26 No. 2, pp. 163-179.

Garofoli, G. (1994), "New firm formation and regional development: the Italian case”, Regional Studies, Vol. 28 No. 4, pp. 381-393.

Gartner, W.B. (1985), "A conceptual framework for describing the phenomenon of new venture creation", Academy of Management Review, Vol. 10 No. 4, pp. 696-706.

Gerba, D.T. (2012), “The context of entrepreneurship education in Ethiopian universities”, Management Research Review, Vol. 35 Nos 3-4, pp. 225-244.

Giacomin, O., Janssen, F., Pruett, M., Shinnar, R.S., Llopis, F. and Toney, B. (2011), "Entrepreneurial intentions, motivations and barriers: differences among American, Asian and European students”, International Entrepreneurship and Management Journal, Vol. 7 No. 2, pp. 219-238.

Goodman, P.S. and Whetten, D.A. (1998), "Fifty years of organizational behavior from multiple perspectives", in Mckelvey, J.A.N.M. (Ed.), Industrial Relations at the Dawn of the New Millennium, New York State School of Industrial and Labor Relations, Ithaca, NY, pp. 32-53.

Gorman, G., Hanlon, D. and King, W.R. (1997), "Some research perspectives on entrepreneurship education, enterprise education and education for small business management: a ten-year literature review", International Small Business Journal, Vol. 15 No. 3, pp. 56-78.

Greenwood, R. and Suddaby, R. (2006), "Institutional entrepreneurship in mature fields: the big five accounting firms", Academy of Management Journal, Vol. 49 No. 1, pp. 27-48.

Guerrero, M., Urbano, D. and Gajón, E. (2014), "The internal pathways that condition university entrepreneurship in Latin America: an institutional approach", in Hoskinson, S. and Kuratko, D.F. (Eds), Innovative Pathways for University Entrepreneurship in the 21st Century (Advances in the Study of Entrepreneurship, Innovation and Economic Growth, Vol. 24), Emerald Group Publishing Limited, Bingley, pp. 89-118.

Haddad, G., Esposito, M. and Tse, T. (2016), “The social cluster of gender, agency and entrepreneurship”, International Journal of Entrepreneurship and Small Business, Vol. 28 No. 4, pp. 431-450.

Henry, C. and Lewis, K. (2018), "A review of entrepreneurship education research: exploring the contribution of the Education + Training special issues", Education + Training, Vol. 60 No. 3, pp. 263-286.

Hofstede, G.H. (2001), Culture's Consequences: Comparing Values, Behaviors, Institutions and Organizations across Nations, Sage Publications, Thousand Oaks, London and New Delhi.

Jack, S.L. and Anderson, A.R. (2002), "The effects of embeddedness on the entrepreneurial process", Journal of Business Venturing, Vol. 17 No. 5, pp. 467-487.

Johannisson, B. (2016), "Limits to and prospects of entrepreneurship education in the academic context", Entrepreneurship \& Regional Development, Vol. 28 Nos 5-6, pp. 403-423.

Johnson, D., Craig, J.B.L. and Hildebrand, R. (2006), "Entrepreneurship education: towards a disciplinebased framework", Journal of Management Development, Vol. 25 No. 1, pp. 40-54.

Kaufmann, H.R. (2009), "The contribution of entrepreneurship to society", International Journal of Entrepreneurship and Small Business, Vol. 7 No. 1, pp. 59-73.

Kuratko, D.F. (2003), "Entrepreneurship education: emerging trends and challenges for the 21st century", 2003 Coleman Foundation White Paper Series for the US Association of Small Business \& Entrepreneurship.

Kuratko, D.F. and Morris, M.H. (2018), "Examining the future trajectory of entrepreneurship”, Journal of Small Business Management, Vol. 56 No. 1, pp. 11-23.

Lackéus, M. and Williams Middleton, K. (2018), “Assessing experiential entrepreneurship education: key insights from five methods in use at a venture creation program", in Hyams-Ssekasi, D. and Caldwell, E. (Eds), Experiential Learning for Entrepreneurship: Theoretical and Practical Perspectives in Enterprise Education, Palgrave Macmillan, Cham, pp. 19-49. 
Lackéus, M., Lundqvist, M. and Williams Middleton, K. (2016), "Bridging the traditional-progressive education rift through entrepreneurship", International Journal of Entrepreneurial Behavior \& Research, Vol. 22 No. 6, pp. 777-803.

Latour, B. (2005), Reassembling the Social: An Introduction to Actor-Network-Theory, Oxford University Press, Oxford.

Lave, J. (2009), "The practice of learning", in Illeris, K. (Ed.), Contemporary Theories of Learning: Learning Theorists... in Their Own Words, Routledge, London, pp. 200-208.

Lee, S.M., Lim, S.B., Pathak, R.D., Chang, D. and Li, W. (2006), "Influences on students attitudes toward entrepreneurship: a multi-country study", International Entrepreneurship and Management Journal, Vol. 2 No. 3, pp. 351-366.

Leitch, C., Hazlett, S.A. and Pittaway, L. (2012), "Entrepreneurship education and context", Entrepreneurship and Regional Development, Vol. 24 Nos 9-10, pp. 733-740.

Libombo, D.B. and Dinis, A. (2015), "Entrepreneurship education in the context of developing countries: study of the status and the main barriers in Mozambican higher education institutions", Journal of Developmental Entrepreneurship, Vol. 20 No. 3, pp. 1-27.

Longva, K.K. and Foss, L. (2018), "Measuring impact through experimental design in entrepreneurship education: a literature review and research agenda", Industry and Higher Education, Vol. 32 No. 6, pp. 358-374.

Maritz, A. and Brown, C.R. (2013), "Illuminating the black box of entrepreneurship education programs", Education + Training, Vol. 55 No. 3, pp. 234-252.

Mars, M.M. and Ginter, M.B. (2012), "Academic innovation and autonomy: an exploration of entrepreneurship education within American community colleges and the academic capitalist context", Community College Review, Vol. 40 No. 1, pp. 75-95.

Matlay, H. (2006), "Researching entrepreneurship and education: Part 2: what is entrepreneurship education and does it matter?", Education + Training, Vol. 48 Nos 8-9, pp. 704-718.

Matlay, H. and Carey, C. (2007), "Entrepreneurship education in the UK: a longitudinal perspective", Journal of Small Business and Enterprise Development, Vol. 14 No. 2, pp. 252-263.

Moroz, P.W. and Hindle, K. (2011), "Entrepreneurship as a process: toward harmonizing multiple perspectives", Entrepreneurship Theory and Practice, Vol. 36 No. 4, pp. 781-818.

Mueller, S.L. and Thomas, A.S. (2001), "Culture and entrepreneurial potential: a nine country study of locus of control and innovativeness", Journal of Business Venturing, Vol. 16 No. 1, pp. 51-75.

Muñoz, P. and Cohen, B. (2017), "Towards a social-ecological understanding of sustainable venturing”, Journal of Business Venturing Insights, Vol. 7, pp. 1-8.

Mwasalwiba, E.S. (2010), "Entrepreneurship education: a review of its objectives, teaching methods, and impact indicators", Education + Training, Vol. 52 No. 1, pp. 20-47.

Mwasalwiba, E.S., Groenewegen, P. and Wakkee, I. (2014), "University entrepreneurship education in Tanzania: introducing entrepreneurship education in a context of transition”, in Fayolle, A. and Redford, D.T. (Eds), Handbook on the Entrepreneurial University, Edward Elgar, Cheltenham, pp. 136-162.

Nabi, G., Liñán, F., Krueger, N., Fayolle, A. and Walmsley, A. (2017), "The impact of entrepreneurship education in higher education: a systematic review and research agenda", Academy of Management Learning \& Education, Vol. 16 No. 2, pp. 277-299.

Naia, A., Baptista, R., Januário, C. and Trigo, V. (2014), "A systematization of the literature on entrepreneurship education: challenges and emerging solutions in the entrepreneurial classroom", Industry and Higher Education, Vol. 28 No. 2, pp. 79-96.

Naia, A., Baptista, R., Januário, C. and Trigo, V. (2015), "Entrepreneurship education literature in the 2000s", Journal of Entrepreneurship Education, Vol. 18 No. 1, pp. 111-135.

Neck, H.M. and Greene, P.G. (2011), "Entrepreneurship education: known worlds and new frontiers", Journal of Small Business Management, Vol. 49 No. 1, pp. 55-70. 
Neergaard, H. and Christensen, D.R. (2017), "Breaking the waves: routines and rituals in Entrepreneurship entrepreneurship education", Industry and Higher Education, Vol. 31 No. 2, pp. 90-100.

Neumeyer, X. and Mckenna, A. (2016), "Entrepreneurial thinking in interdisciplinary student teams", Advances in Engineering Education, Vol. 5 No. 1, pp. 1-20.

Newbery, R., Lean, J. and Moizer, J. (2016), "Evaluating the impact of serious games: the effect of gaming on entrepreneurial intent", Information Technology and People, Vol. 29 No. 4, pp. 733-749.

Noyes, E. and Deligiannidis, L. (2012), "2D and 3D visualizations of creative destruction for entrepreneurship education”, in Hippe, Z.S., Kulikowski, J.L. and Mroczek, T. (Eds), Advances in Intelligent and Soft Computing, Springer, Berlin, pp. 277-294.

Obrecht, J.J. (2016), "Sustainable entrepreneurship education: a new field for research in step with the 'effectual entrepreneur", International Journal of Entrepreneurship and Small Business, Vol. 29 No. 1, pp. 83-102.

Ollila, S. and Williams-Middleton, K. (2011), "The venture creation approach: integrating entrepreneurial education and incubation at the university", International Journal of Entrepreneurship and Innovation Management, Vol. 13 No. 2, pp. 161-178.

Pavlova, I. and Chernobuk, V. (2016), "Project education in entrepreneurial universities: an exploratory analysis", Proceedings of the 28th International Business Information Management Association Conference - Vision 2020: Innovation Management, Development Sustainability, and Competitive Economic Growth, pp. 3196-3204.

Petticrew, M. and Roberts, H. (2006), Systematic Reviews in the Social Sciences: A Practical Guide, Blackwell Publishing, Malden, Oxford, Carlton.

Pittaway, L. and Cope, J. (2007), "Entrepreneurship education - a systematic review of the evidence", International Small Business Journal, Vol. 25 No. 5, pp. 479-510.

Pittaway, L. and Thorpe, R. (2012), "A framework for entrepreneurial learning: a tribute to Jason Cope", Entrepreneurship \& Regional Development, Vol. 24 Nos 9-10, pp. 837-859.

Rautamäki, H. and Römer-Paakkanen, T. (2016), "The next generation's commitment and willingness to continue the family business: reflecting on potential successors' experiences and pondering", International Journal of Entrepreneurship and Small Business, Vol. 27 No. 1, pp. 52-70.

Robinson, S., Neergaard, H., Tanggaard, L. and Krueger, N.F. (2016), "New horizons in entrepreneurship education: from teacher-led to student-centered learning", Education + Training, Vol. 58 Nos 7-8, pp. 661-683.

Sarasvathy, S.D. and Dew, N. (2005), "Entrepreneurial logics for a technology of foolishness", Scandinavian Journal of Management, Vol. 21 No. 4, pp. 385-406.

Seikkula-Leino, J., Ruskovaara, E., Ikavalko, M., Mattila, J. and Rytkola, T. (2010), "Promoting entrepreneurship education: the role of the teacher?", Education + Training, Vol. 52 No. 2, pp. 117-127.

Shrivastava, P. and Kennelly, J.J. (2013), "Sustainability and place-based enterprise”, Organization \& Environment, Vol. 26 No. 1, pp. 83-101.

Solomon, G. (2007), "An examination of entrepreneurship education in the United States”, Journal of Small Business and Enterprise Development, Vol. 14 No. 2, pp. 168-182.

Solymossy, E. and Hisrich, R.D. (2000), "Entrepreneurial dimensions: the relationship of individual, venture, and environmental factors to success", Entrepreneurship Theory and Practice, Vol. 24 No. 4, pp. 79-80.

Thestrup, K. and Robinson, S. (2016), “Towards an entrepreneurial mindset: empowering learners in an open laboratory", in Papadopoulos, P.M., Burger, R. and Faria, A. (Eds), Inovation and Entrepreneurship in Education, Advances in Digital Education and Lifelong Learning, Vol. 2, Emerald, Bingley, pp. 147-166.

Thongpravati, O., Maritz, A. and Stoddart, P. (2016), "Fostering entrepreneurship and innovation through a biomedical technology $\mathrm{PhD}$ program in Australia", International Journal of Engineering Education, Vol. 32 No. 3, pp. 1222-1235. 


\section{IJEBR}

Table AI.

Journals publishing context entrepreneurship education articles
Tranfield, D., Denyer, D. and Smart, P. (2003), "Towards a methodology for developing evidence informed management knowledge by means of systematic review", British Journal of Management, Vol. 14 No. 3, pp. 207-222.

Walter, S.G. and Dohse, D. (2012), "Why mode and regional context matter for entrepreneurship education”, Entrepreneurship \& Regional Development, Vol. 24 Nos 9-10, pp. 807-835.

Walter, S.G., Parboteeah, K.P. and Walter, A. (2010), "University departments and entrepreneurial intentions: a cross-level analysis", Academy of Management - Dare to Care: Passion and Compassion in Management Practice and Research Montreal, Academy of Management, Briarcliff Manor, NY, pp. 1-6.

Walter, S.G., Parboteeah, K.P. and Walter, A. (2013), "University departments and self-employment intentions of business students: a cross-level analysis", Entrepreneurship Theory and Practice, Vol. 37 No. 2, pp. 175-200.

Welter, F. (2011), "Contextualizing entrepreneurship - conceptual challenges and ways forward", Entrepreneurship Theory and Practice, Vol. 35 No. 1, pp. 165-184.

Welter, F., Gartner, W.B. and Wright, M. (2016), "The context of contextualizing contexts", in Welter, F. and Gartner, W.B. (Eds), A Research Agenda for Entrepreneurship and Context, Edward Elgar, Cheltenham, pp. 1-15.

Williams Middleton, K. and Donnellon, A. (2014), "Personalizing entrepreneurial learning: a pedagogy for facilitating the know why", Entrepreneurship Research Journal, Vol. 4 No. 2, pp. 167-204.

Xie, C. and Wang, J. (2014), "Entrepreneurship education and venture creation: the role of the social context", Journal of Entrepreneurship Education, Vol. 17 No. 1, pp. 83-99.

Zahra, S.A., Wright, M. and Abdelgawad, S.G. (2014), "Contextualization and the advancement of entrepreneurship research", International Small Business Journal, Vol. 32 No. 5, pp. 479-500.

Zhang, S. (2015), "A technology-business-environment model for effective internet entrepreneurship education", 2015 12th International Conference on Information Technology-New Generations IEEE, pp. 632-637.

\section{Appendix 1}

Journal

Number of articles

"Entrepreneurship Education” and "Context"

Education and Training

Journal of Entrepreneurship Education

Entrepreneurship and Regional Development

International Journal of Management Education

Journal of Small Business and Enterprise Development

International Journal of Entrepreneurial Behaviour and Research

International Journal of Entrepreneurship and Small Business

Journal of Entrepreneurship in Emerging Economies

Journal of Business Venturing

Journal of Enterprising Communities

Small Business Economic

Technological Forecasting and Societal Change 


\begin{tabular}{|c|c|c|c|}
\hline \multicolumn{2}{|l|}{ Countries } & \multirow{2}{*}{$\frac{\text { Regions }}{\text { Europe }}$} & \\
\hline Albania & Korea & & \\
\hline Australia & Malaysia & USA & \\
\hline Austria & Morocco & North America & \\
\hline Austria & Nicaragua & Asia & \\
\hline Bangladesh & North Ireland & Arab Countries & \\
\hline Chile & Peru & & \\
\hline China & Poland & & \\
\hline Denmark & Portugal & & \\
\hline Egypt/Jordan/Oman/Tunesia & Romania & & \\
\hline Estonia & Singapore & & \\
\hline Ethiopia & South Africa & & \\
\hline Finland & Spain & & \\
\hline Germany & Sweden & & \\
\hline Greece & Turkey & & \\
\hline Holland & UK & & Table AII. \\
\hline India & Ukraine & & Countries and regions \\
\hline Ireland & United Arab Emirates & & represented in the \\
\hline Japan & USA & & literature \\
\hline
\end{tabular}

\section{About the authors}

Mette Lindahl Thomassen is currently PhD Student at Aarhus University, MSc in Marketing, is Associate Professor at VIA Engineering, VIA University College, Denmark. Mette is the former Coordinator of VIA Student Incubator. Her field of research is entrepreneurship education where she often takes an outset in discussions about new roles for educators in higher education and how the field can be advanced. She has presented her work at several international conferences in both entrepreneurship education and engineering fields. Her primary research interests lay in teaching and learning entrepreneurship in higher education and engineering education. Mette Lindahl Thomassen is the corresponding author and can be contacted at: melt@via.dk

Karen Williams Middleton is Associate Professor in Entrepreneurship in the division Entrepreneurship and Strategy at Chalmers University of Technology. Her research interests include nascent entrepreneurship, entrepreneurial identity and behaviour, entrepreneurial learning and education and university entrepreneurship. She has been Faculty at Chalmers School of Entrepreneurship since 2004. Her research has been published in, for example, Journal of Small Business and Enterprise Development, International Journal of Entrepreneurial Behaviour and Research, International Journal of Management Education and International Journal of Entrepreneurship and Innovation Management among others.

Michael Breum Ramsgaard is currently PhD Student at Aarhus University, MA (Education), is Associate Professor at Faculty of Health Sciences, VIA University College, Aarhus, Denmark. He has 15 years of development experience in the area of entrepreneurship education, entrepreneurial learning and innovation management. In 2015, he was awarded a prize for his work from Danish Society for Entrepreneurship and Business. His research interests are all within entrepreneurship education, with a special focus on experiential learning, entrepreneurial leadership and identity. His research has been published in Innovations in Education and Teaching International and Education + Training.

Helle Neergaard is Professor of Entrepreneurship at Aarhus University in Denmark. She has 20 years of experience in researching and teaching entrepreneurship and is European Entrepreneurship Educator Laureate 2018. Her main research interests are in entrepreneurship education and gender studies and her research has been published in, e.g. Entrepreneurship Theory and Practice, 
International Small Business Journal, International Journal of Entrepreneurial Behaviour and Research and International Journal of Gender and Entrepreneurship. She is also the editor of two handbooks on qualitative research methods in entrepreneurship published by Edward Elgar.

Until July 2018, Lorraine Warren was Professor of Innovation and Entrepreneurship at Massey University in New Zealand. She has 25 years of educational development experience in entrepreneurship and innovation, at universities in the UK as well as New Zealand. She has also been an advisor in Pakistan, Russia and Romania. Her experience includes high technology, creative industries, social enterprise and indigenous enterprise. Her research interests reflect these areas, focusing on entrepreneurial identity and how entrepreneurs are represented in the media.

For instructions on how to order reprints of this article, please visit our website: 